$$
\text { "tmcs-szeredi"II" — 2012/2/27 — 20:12 — page } 1 \text { - \#1 }
$$

\title{
Forming the concept of congruence II.
}

\author{
Éva SZEREDI
}

\begin{abstract}
This paper is a continuation of the article Forming the concept of congruence I., where I gave theoretical background to the topic, description of the traditional method of representing the isometries of the plane with its effect on the evolution of congruence concept.

In this paper I describe a new method of representing the isometries of the plane. This method is closer to the abstract idea of 3-dimensional motion. The planar isometries are considered as restrictions of 3-dimensional motions and these are represented with free translocations given by flags.

About the terminology: I use some important concepts connected to teaching of congruence, which have to be distinguished. My goal is to analyse different teaching methods of the 2-dimensional congruencies. I use the term 3-dimensional motion for the orientation preserving (direct) 3-dimensional isometry (which is also called rigid motion or rigid body move). When referring the concrete manipulative representation of the planar congruencies I will use the term translocation.
\end{abstract}

Key words and phrases: teacher education, concept formation, acquisition of mathematical concepts, transformation geometry, manipulative materials, teaching methods and classroom techniques.

ZDM Subject Classification: B50, C30, E40, G50, Q60, U60.

A method, based strictly on the concept of 3-dimensional motions

Geometric moves (demonstrated by using transparent paper) are represented in a non-traditional way in our method, we will refer to them as free translocations given by flags. The basic idea of this kind of representation came from Collier (1976), who described a way of using tracing paper in his book - Geometry for

Copyright (C) 2012 by University of Debrecen 
teachers ${ }^{1}-$, which was new to me. At that time in my college teaching practice I had already experienced deep misconceptions in connection with the congruence correspondences, and I realized that Collier's method can be generalized in order to fit the axioms of 3-dimensional motion. So I worked out a new approach which was gradually refined with the help of colleagues - J. Török and Csongorné Kovács. Using this method we created a set of teaching materials, which, after having been tried in 100 classes in an experiment (from 1999 to 2003), became part of a series of textbooks (for children from 10 to 14).

\section{Planar isometries as 3-dimensional motions and their representation by free translocation given by flags}

In this method of teaching isometries to schoolchildren, we use two "flags" in order to define a congruence of the plane. Each flag consists of a segment (the rod) and of an attached triangle. The flags are of the same shape and size, but one is white and the other is black. We also use tracing paper. An example is shown in Figure 1. (Note that the two rods coincide here.)

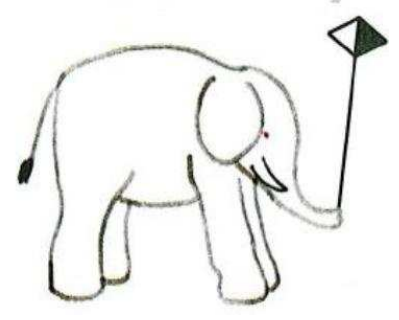

Figure 1. Axial reflection given by flags

\footnotetext{
1 "Suppose you are given a plane figure $A$ and a line $l$, and are asked to reflect it in line $l$. How might you find the reflection of figure $A$ in line $l$ ? One method involves the use of tracing paper and requires you to follow these steps:

(1) Place tracing paper over figure $A$ and the line $l$; trace figure $A$, line $l$ and reference point $P$.

(2) Pick up your tracing paper and turn it over so that the tracing of line $l$ coincides with the original line $l$ and the tracing of point $P$ coincides with point $P$.

(3) The "reflection" of figure $A$ can be seen through the tracing paper. If you want a permanent copy of the reflection you can transfer it to your original drawing with carbon paper."

(P. Collier: Geometry for teachers, p. 123)
} 
To get the image of a certain shape we first trace the shape together with the white flag. Next, we lift the paper and translocate the white flag on the tracing paper coincide with the black one. If, after this, we trace the original shape on the tracing paper again, then we obtain the original shape together with its transformed image. (See Figure 2)

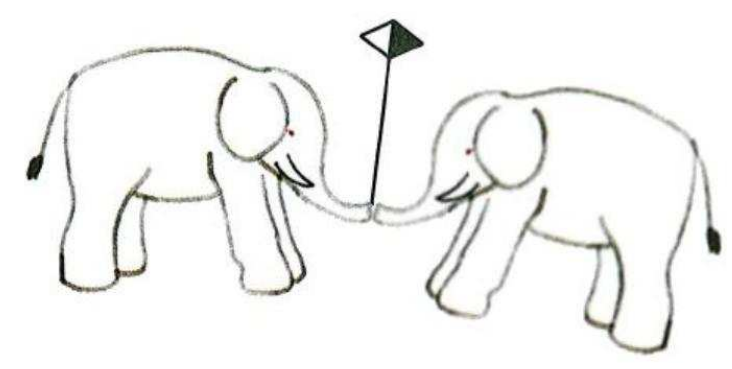

Figure 2. Axial reflection using flags

In this method the route of the translocation is not determined, only the initial and the final position of the moving plane. In this method the tracing paper, if not folded, ripped, stretched, shrunk ..., is a natural representation of axiom VII of Hajós. It represents a mobile plane.

The flag represents a ray with one of the half-planes belonging to it. If we take the ray given by the rod of the flag, starting from the bottom of it, and take the half-plane given by the triangle of the flag, we get two half-planes with rays on their boundary line, and these define a single move, as it is stated in the axiom VIII. of Hajós.

This representation is in accordance with the early experiences of children about the "sameness" - i.e. the congruence - of the shapes. At the same time it agrees with the exact definition of congruence, namely that distances of two pairs of points are equal if the pairs of points can be made to coincide by a 3-dimensional motion.

Let us see how the special isometries can be defined this way: Example 4 (Szeredi, Kovács, 2002, p): Axial reflection

"There is a given line $t$ - the axis. The axial reflection to this axis is a motion which leaves all the points of the axis fixed and swaps the two half-planes defined by it."

This definition is quoted from a textbook for 6-th grade children (aged 12 years) and is almost equivalent to the definition of the axial reflection in Hajós's 
book (1971. p. 43) However, it is more difficult to give an exact definition of a rotation as a restriction of a 3 -dimensional motion.

Example 5 Rotation (see Figure 3)

There is given a centre $O$ and an oriented angle AOB. Move the first arm of the angle, ray $O A$, onto the second arm of the angle, ray $O B$, and the half-plane, bounded by $O A$ and containing ray $O B$, onto the half-plane bounded by $O B$ and not containing ray $O A$.

This exact mathematical definition is hard to digest by schoolchildren but it becomes easy if we give it with the help of flags. The same correspondence, first given by an oriented angle, second specified using flags, is shown in Figure 3.
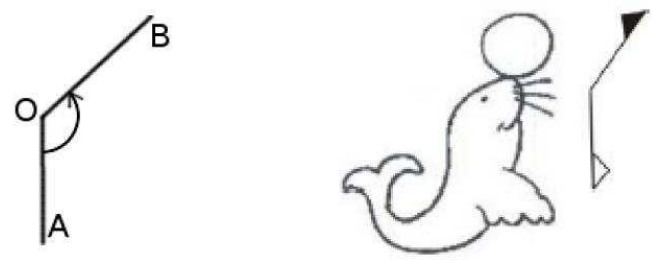

Figure 3. Rotation using flags (Sulinova, 2008)

These examples show that defining a motion given by flags is based directly on axioms of Euclidian geometry. It is not only an illustration, like folding, cutting, rotating around a fix point etc. It is a correct mathematical definition, but represented in a way which is natural for and close to the children's thinking. Therefore, it seems appropriate for building the concept of congruence on it.

\section{The representation by free translocation}

In the following analysis I use axial reflection as the main example.

In this method the axial reflection is introduced as translocation with the help of flags. This is practised for a time long enough to derive the main properties of the axial reflection and the corresponding point-by-point definition.

Having introduced this definition, the children learn how to construct the images of points, straight lines, and circles using ruler and compass.

Because in this method the definition of reflection as a 3 dimensional motion is correct and at the same time the corresponding translocation is easy to carry out, it can be used conveniently for producing the corresponding image of shapes. 
Therefore this kind of translocations can be used as substitutes of the ruler and compass constructions for a long time, parallel with them. This way the children can get abundant amount of experiences about the corresponding congruent images, belonging to the isometries, enough to support strong inner representation of different types of isometries.

\section{The representation by free translocation and the procept of congruence}

This method also contains all the elements of procept formation.

Activities and procedures are basic elements of this method. Symbols are used, and a mathematical object is created.

- The main process is the moving of a tracing paper.

- The symbol is either the given axis $t$, either the twin picture of shape and image. (Later it can be a formal designation, like $R_{t}$, meaning reflection in line $t$.)

- The object is the pair of shape and its congruent image.

The concept is the congruence correspondence between these shapes.

In this new method the first step is learning the procedure of creating the corresponding image of a shape with the help of tracing paper. The transformation of a whole shape happens in a single movement and so it creates a strong image of the workings of the transformation. Symbol and process are linked from the beginning. This is work on the visual level (in the sense of van Hiele).

While performing these activities, there is time and opportunity for the procedure to "... become an entity - a thing" (Davis, 1984). Another quote from the same article of Davis describes the next step of procept formation: when the procedure becomes an entity, then "it, itself, is an input or object of scrutiny. All of the full range of perception, analysis, pattern recognition and other information processing capabilities that can be used on any input data can be brought to bear on this particular procedure. Its similarities to some other procedure can be noted, and also its key points of difference. The procedure, formerly only a thing to be done - a verb - has now become an object of scrutiny and analysis; it is now, in this sense, a noun." 


\section{From the process to the abstract concept}

Having got familiar with the free translocations using flags, the process of creating the image becomes an object of scrutiny. We can start looking for corresponding details in the shape and in the image. Not just corresponding points, but corresponding angles, corresponding line segments, corresponding arcs, corresponding triangles, etc. Having chosen a candidate pair of details in the picture, children can easily check, if these really correspond to each other, by using the tracing paper. In this phase children work on the analytic level of van Hiele.

Example 6 (Szeredi, Kovács, 2003):

We highlighted some corresponding details in the picture (Figure 4) with different colours. Try to find other corresponding pairs in it.

(Note that the original picture is in colour. The two corresponding arcs on the frame are yellow; the two corresponding angles at the top of the windows are red; the two corresponding points, $A$ and $A^{\prime}$, are blue; and the two corresponding line segments, $O P$ and $O^{\prime} P^{\prime}$, are green in the textbook)

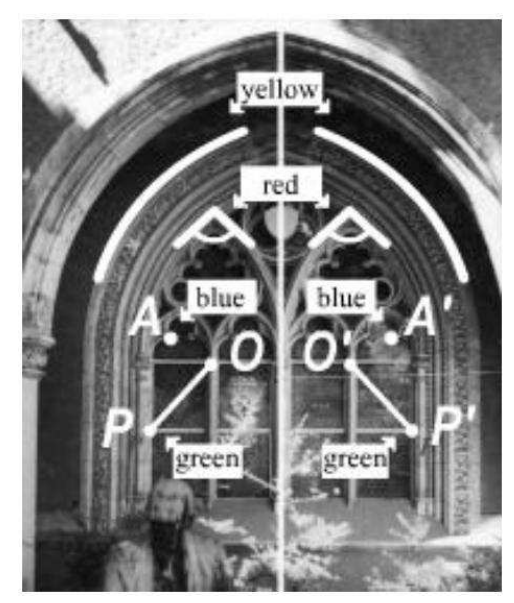

Figure 4. Corresponding details

The statement that corresponding details are congruent, is in accordance both with the intuitive concept of the child and with the exact definition of the congruence of shapes.

In this method the symbol, the picture of the shape and of its image, is linked to both the process and the concept. 
When the procept is formed, it only needs to be reinforced, exercised, applied, embedded into a scheme. The procept, evolving this way, serves as a basis for further work on informal deduction level of van Hiele.

By the next set of textbook examples I would like to show that being able to perceive the corresponding details of a certain congruence is an especially important step in the formation of the congruence concept.

Consider a line segment with one of its end points on the axis. Its corresponding image is a line segment in the other half-plane with the same end point on the axis. Furthermore, the angle between this segment and the axis corresponds to the angle in the other half-plane between the image segment and the axis. So these segments and angles are congruent. From this observation, it is easy to derive the following statements:

Example 7 (Szeredi, Kovács, 2003):

"The points of the axis are equally far from a point $P$ and from its axial image $P^{\prime}$."

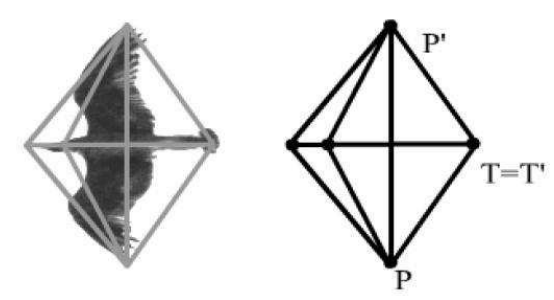

Figure 5. Properties of axial reflection

"A straight line and its image cross each other on the axis and they lean to the axis at the same angle."

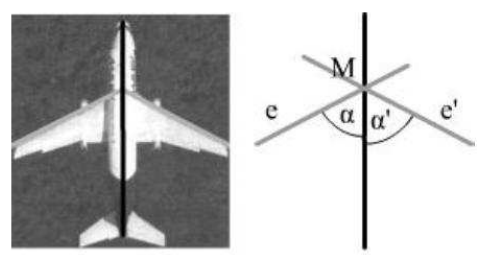

Figure 6. Properties of axial reflecion
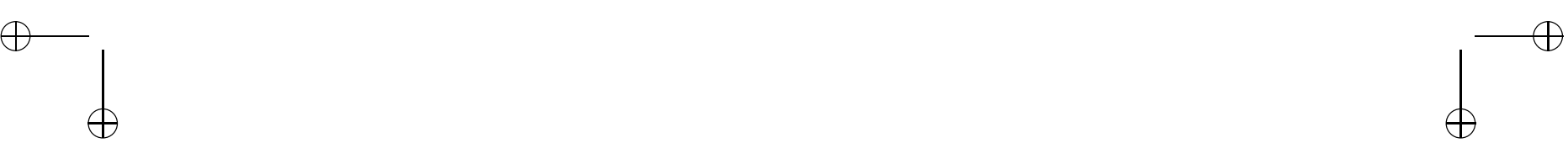
If these findings are properly understood, children may become able to devise different strategies for constructing the axial image of a point, using ruler and compass. $^{2}$

These observations also lead to some other important statements.

Let we connect a point and its image, the connecting line segment crosses the axis. (see Figure 7). When we look for corresponding details in the drawing, we find that the segment from the point $P$ to the axis corresponds to the segment from the image point $P^{\prime}$ to the axis. So the axis bisects the segment $P P^{\prime}$.

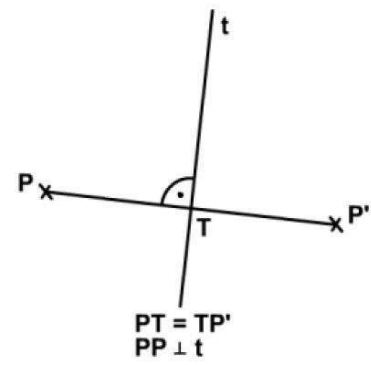

Figure \%. Properties of axial reflection

One angle at the crossing point corresponds to the angle on the other side, and they add up to $180^{\circ}$, so both have to be $90^{\circ}$. Therefore, the axis is the bisecting perpendicular of the line segment connecting a point with its image.

Taken together with the statement of Figure 5, this means that the points of a bisecting perpendicular are equally far from the two end points.

If we choose three points (which are not colinear), such that two of them are reflective images of each other (but not points of the axis) and the third is on the axis, then these points make up a triangle. This triangle is symmetrical regarding the axis. If the children have already got practice in looking for corresponding details, they will find out all the properties of the isosceles triangle.

${ }^{2}$ Here are some examples of strategies created by $6^{\text {th }}$ grade pupils for constructing the axial image of a given point $P$.

- Take two points - $A$ and $B$ - arbitrarily on the axis and draw circle around $A$ with a radius $A P$ and another circle around $B$ with the radius $B P$. The crossing of the two circles gives $P^{\prime}$, the image of $P$.

- Connect $P$ with an arbitrary point $A$ of the axis. Copy the angle between $A P$ ray and the axis to the other side of the axis at the same vertex. Measure the distance $A P$ on the new arm of the angle (on the axial image of the $A P$ ray) in order to get the $P^{\prime}$ image of $P$. 
Example 8 (Szeredi, Kovács, 2003): see Figure 8.

(The slightly different shades in the figures are easily distinguishable colours in the textbook.)

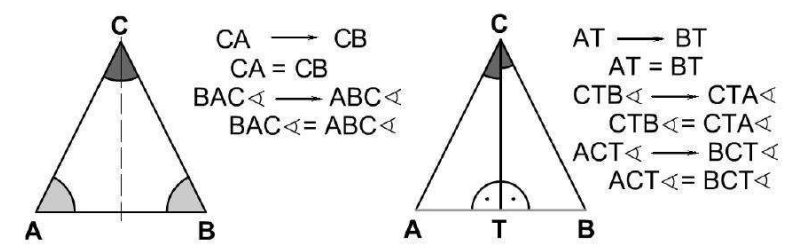

Figure 8. Properties of symmetrical triangles

Similar considerations work for reflection invariant quadrilaterals: kites, reflection symmetrical trapeziums, rhombuses, rectangles and squares. If the children are able to recognize the corresponding details in a symmetrical shape, then other properties of these shapes can be easily derived from the symmetry property. The drawing in Figure 9 shows how the properties perceived this way can be condensed into symbols.

Example 9 (Szeredi, Kovács, 2003):

(The slightly different shades on the figures are easily distinguishable colours in the textbook.)
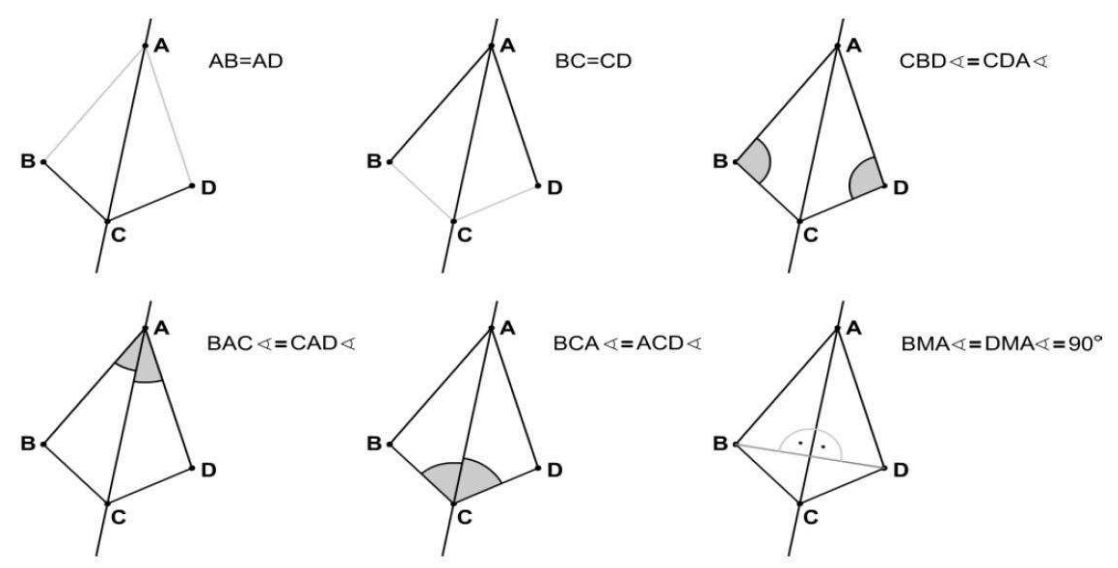

Figure 9. Properties of symmetrical quadrilaterals

With the help of the flags it is very easy to generate any isometries of the plane including the slide reflection. 
Example 10 (Kovács, Szeredi, 2003):

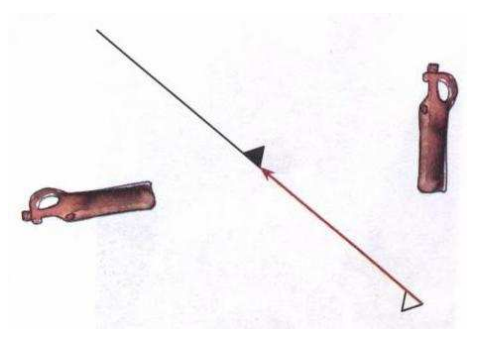

Figure 10. Slide-reflection

It is relatively easy for the children to find corresponding details in pictures with axial symmetry, but it is a lot more difficult for them in case of other types of symmetries, like central or rotational symmetry. That is probably the reason behind the difficulty of teaching statements about the properties of the parallelogram although these statements play basic role in deductive geometric reasonings.

In the method, when the translocations are given by flags, the tracing paper is a simple and efficient tool to find the corresponding details in the case of central or rotational symmetry too. That makes the teaching of the properties of the parallelogram - the central reflection invariant quadrilateral - a natural continuation of their previous studies about axial symmetry.

As the examples show, if taught by this method, the can children work on the van Hiele level of informal deduction even in their lower secondary ages (from grades 6.-7.).

We have to add that these types of reasoning are not that easy for the converse statements, i.e.: to prove the symmetry property from the congruence of certain sides and angle. These kinds of deductions appear only in the later classes, and can be carried out only by more able children.

Éva Vásárhelyi (2007) gives a detailed analysis of how the symmetry-based introduction of polygons influences the evolution of the concept of quadrilaterals, from the comprehensive education up to the university geometry courses. She distinguishes three levels in the classification of quadrilaterals: those based on symmetry properties, on metric properties, and on axiomatic approach. She shows that the extension of the concept does not lead to a contradiction at any of the changes between levels. 


\section{Conclusion}

In the paper I presented a non-traditional approach of building the foundations of the concept of congruence. This approach is based on the concept of 3-dimensional motion.

I compared this method with earlier approaches. The main difference between these approaches is in the role of representations, especially in the strictness of the analogy between representation and the abstract concept.

I showed that, representing isometries with free translocations given by flags, using tracing paper, the young children's intuitive, process based concept and the exact definition of congruence can be put together without conflicting, rather completing each other. This method can help the evolution of a proper concept of congruence, which

- has strong connections with the children's everyday experiences;

- is accurate and applicable in deductive reasoning;

- makes easy to carry out argumentations based on symmetry properties;

- helps in the development of a clear understanding of equivalence of transformations;

- influences the children's comprehension of other areas as well, for example, it leads to a better understanding of the equivalence of functions in general.

Naturally it is necessary to classify isometries in some other ways as well, for example regarding the orientation. It is only an introduction which provides a stabil and open basic knowledge which can be developed further without contradiction.

\section{References}

[1] A. Ambrus, Some trends in Hungarian geometry teaching, In: Perspectives on the teaching of geometry for the 21st century, pre-proceedings for Catania Conference, Department of Mathematics - University of Catania, 1995.

[2] T. Andrássy, T. Czeglédy, I. Czeglédy, S. Hajdu and L. Novák, Matematika 7. osztály, Mathematics textbook, grade 7, Calibra Kiadó, Budapest, 1994.

[3] J. S. Bruner, Toward a Theory of Instruction, The Belknap Press of Harvard University Press, Cambridge - Massachusetts, 1971.

[4] C. P. Collier, Geometry for teachers, Houghton Mifflin Company, Boston, 1976.

[5] J. Cotrill, E. Dubinsky, D. Nichols, K. Schwingendorf, K. Thomas and D. Vidakovich, Understanding the limit concept, Beginning with a coordinated process schema, Journal of Math. Behaviour 15, 1996. 
[6] R. B. Davis, Learning mathematics: the cognitive science approach to mathematics education, Ablex, Norwood, NJ, 1984.

[7] Euklidesz, : Elemek, Elements, Translation of Szabó Árpád, Gondolat, Budapest, 1983.

[8] T. Gallai and R. Péter, Matematika a középiskolák I. osztálya számára, Mathematics for the grade I of secondary schools, Tankönyvkiadó, Budapest, 1952.

[9] E. M. Gray and D. O. Tall, Duality, Ambiguity and Flexibility in Successful Mathematical Thinking, In: Proceedings of PME-XV. vol. 2, Assisi, Italy, 1994.

[10] Gy. Hajós, Bevezetés a geometriába, Introduction to geometry, Tankönyvkiadó, Budapest, 1971.

[11] H. Meissner, Procepts in geometry, In: European Research in Mathematics Education II, 2001.

[12] I. Reimann, A geometria határterületei, Topics from the frontiers of geometry, Gondolat Kiadó, Budapest, 1986.

[13] A. Sfard, Two conceptions of mathematical notions: operational and structural, In: Proceedings of PME-XIII. vol. 3, Montreal, Canada, 1987.

[14] Sulinova Educatio Kht, 2008, Packages of materials for teaching mathematics, http://www. sulinovadatbank.hu/index.php.

[15] É. Szeredi and Cs. Kovács, Geometric transformations, In: E. Csahóczi,K. Csatár, Cs. Kovács, É. Morvai, G. Széplaki, É. Szeredi: Matematika 6. osztály (Mathematics textbook for 6. grade), Apáczai Kiadó, Celldömölk, Hungary, 2002.

[16] É. Szeredi and Cs. Kovács, Geometric transformations, In: E. Csahóczi,K. Csatár, Cs. Kovács, É. Morvai, G. Széplaki, É. Szeredi: Matematika 7. osztály (Mathematics textbook for 7. grade), Apáczai Kiadó, Celldömölk, Hungary, 2003.

[17] D. O. Tall and S. Vinner, Concept image and concept definition in mathematics, with special reference to limits and continuity, Educational Studies in Mathematics 12, 1981.

[18] D. O. Tall, Advanced Mathematical Thinking, Kluwer Academic Publishers, Dordrecht, NL, 1991.

[19] P. van Hiele, The Child's Thought and Geometry, Brooklyn, NY: City University of New York, 1959.

[20] É. Vásárhelyi, Problem solving with the help of different representations, Learning in Europe, Jena, 2006.

[21] É. Vásárhelyi, Fogalomalkotás és reprezentációk, (Concept formation and representations), 2007.

ÉVA SZEREDI

E-mail: eszeredi@gmail.com

(Received September, 2009) 